\title{
Prevalence and Associated Factors of Needle Stick Injury among Nursing and Midwifery Students an Haramaya and Jigjiga University, Eastern Ethiopia
}

\section{Yeshitila $\mathbf{M}^{1^{*}}$, Mengistie $\mathbf{B}^{2}$, Demessie $\mathbf{A}^{3}$ and Godana $\mathbf{W}^{4}$}

${ }^{1}$ Haramaya University, College of Health and Medical Sciences, School of Nursing and Midwifery

${ }^{2}$ Haramaya University, College of Health and Medical Sciences

${ }^{3}$ Addis Ababa University, College of Health Science

${ }^{4}$ Arba Minch University, College of Medicine and Health Sciences

Rec date: Feb 21, 2015, Acc date: March 23, 2015, Pub date: March 30, 2015

*Corresponding Author: Meron Yeshitila, Haramaya University, College of Health and Medical Sciences, School of Nursing and Midwifery, Ethiopia, Email: wanzanati2011@gmail.com

Copyright: ( 2015 Yeshitila M et al. This is an open-access article distributed under the terms of the Creative Commons Attribution License, which permits unrestricted use, distribution, and reproduction in any medium, provided the original author and source are credited.

\begin{abstract}
Background: In developing countries including Ethiopia, the risk of having work-related injury is 10 to 20 times higher than that of developed countries. In their everyday clinical practice, nurse students are at a great risk of occupational hazards, especially risk of exposure to blood borne pathogens potentially resulting to infections. High levels of occupational hazards are believed to affect students' health and academic performance.
\end{abstract}

Objectives: To assess prevalence of needle stick injury and associated factors among nurse and midwife students during their clinical practice.

Methods: Cross-sectional study design was employed to assess needle stick injuries among randomly selected 600 nurse and midwife students in December 2013. Self-administered questionnaire was used to collect the data. Logistic regression with $\mathrm{OR}$ and $95 \% \mathrm{Cl}$ were computed.

Results: One year self-reported prevalence of one or more needle sticks/sharp injury was $62.8 \%$. The life time risk of needle stick injury was $64.8 \%$. The results of the multivariate analysis indicated that exposure to needle stick/ sharp injury was significantly associated with being male (AOR 1.56, 95\% Cl1.07-2.275), Urban family Residence (AOR 2, 95\% Cl 1.18 - 2.422), Learning about infection prevention (AOR 0.44, 95\% Cl 0.17 - 1.17) and Disassembling used needles before disposal (AOR 1.55, 95\% Cl 1.09-2.204).

Conclusion: The prevalence of needle sticks/sharp injury was very high in the study population. In order to improve the situation, creating awareness about infection prevention before deploying of students to clinical practice is important.

\section{Key words:}

Needle stick; University students; Ethiopia; Injury; Clinical practice

\section{Background}

Globally, exposure to blood and body fluids is a great concern for health care providers and puts major risk for the transmission of infections including human immuno-deficiency virus (HIV), hepatitis B virus (HBV), and hepatitis C virus (HCV) [1]. Furthermore, exposure to disease causing pathogen in blood and body fluids makes a nurse at risk for about 20 other infections that have probability of transmission through a needle stick, including, syphilis, and malaria [2]. Nursing is an enviable and lifesaving profession, but as applicable to other areas of human endeavor, the practitioners are exposed to many occupational hazards, some of which produce physical disabilities while others if care is not taken, may lead to life threatening diseases [3].

The Nursing Education program provides both classrooms and clinical experiences. The greater part of the clinical experiences of the
Nursing and Midwifery student is obtained in the hospitals. They are unrecognized group of health care providers and yet they are more prone to occupational hazards encountered in the hospital setting than other health workers given their limited experience and proficiency in nursing care skills [4].

Despite the growing body of knowledge concerning occupational exposures in practices of nurses, there was little study focusing on needle stick injury among the student population. The aim of this study was therefore to determine prevalence of needle stick injury among nursing and midwifery students.

\section{Methods}

\section{Study area and population}

A Cross sectional study was conducted among nursing and midwifery students at Haramaya and Jigjiga University, Eastern Ethiopia. Haramaya University is one of the oldest universities in Ethiopia located $497 \mathrm{Km}$ from the capital Addis Ababa. Haramaya 
University was founded with the help of Oklahoma State University (OSU) to train agricultural science professionals. Till recent times it was center of excellence in the fields of agriculture. College of health sciences was established in 1996. Since then the college of health sciences trained caderes in different fields including public health, nurses and midwives.

Jigjiga University (JJU) is one of the new higher institutions in Ethiopian which has become operational on 26 March 2007. JJU, the first and only university in Somali National Regional state, is located in Jigjiga city, the capital of the Region. Health science faculty, one of the faculties in Jigjiga University, enroll students in three departments Health officer, Clinical nursing and Midwifery.

The sample size was calculated using single proportion formula with the assumption of $50 \%$ of the population had exposure to needled stick injury $4 \%$ marginal error and $95 \%$ confidence interval. An additional $10 \%$ was added as a contingency to increase power and compensate for possible non response rate the total 660 . Based on proportional allocation students from Haramaya and Jigiga University were included in the study.

\section{Data collection procedures}

First, letter of cooperation was obtained from Haramaya University College of Health and Medical Sciences. Then permission from Haramaya and Jigjiga University School of Nursing and Midwifery was secured and convenient time arranged. Pre-testing of the questionnaire was under taken. Three days of training about how to facilitate and perform the data collection process was given to all data facilitators and supervisors. Pre-testing of the questionnaire was undertaken before the actual data collection. The objective of the study was clearly described to the participants and informed and written consent was obtained. The data were collected simultaneously during class hours to control information contamination. Self-administered structured questionnaire was used to collect data. Ten instructors at the respective universities facilitated the data collection.

\section{Data analysis}

Coding, data entry, cleaning was done by Epi-data Version 6.04 and analysis was performed by using SPSS version 16. Data were entered by double entry into EPI-data by two different data clerks for comparisons. Frequency distributions, greater numbers of responses and percentages were calculated. Associations were examined using multivariate logistic regression. Odds ratios were used as indicators of the strength of association. Bivariate analysis was done primarily and then those variables that show $\mathrm{p}$ value $<0.3$ were selected and entered in to the multivariate analysis to control confounding variables and determine association between the predictors and outcome. P values $<$ 0.05 were considered statistically significant.

\section{Ethical Consideration}

The study protocol was approved by Haramaya University, College of Health and Medical Sciences, Institutional Research Ethics Review Committee before starting the data collection process. Official letters of co-operation were written to all of the concerned bodies. Information on the study was explained to the participants, including the procedures, potential risks and benefits of the study. Informed written consent was obtained from each study participants prior to data collection. The respondents were told that they have the right to refuse or decline participation in the study at any time. Participants' confidentiality of information was assured by excluding names and identification in the questionnaire.

\section{Results}

\section{Socio-demographic characteristics of respondents}

Total of six hundred students participated in this study with a response rate of $90 \%$. The mean age of the respondents was 21.24 years (SD \pm 1.39$)$. Among the respondents $418(69.7 \%)$ were males while $182(30.3 \%)$ were females. The result showed that 359(59.8\%) were nursing students while $241(40.2 \%)$ were midwifery students. Two hundred ninety four respondents (49\%) were from Haramaya university and 306 (51\%) were from Jigjiga university. Table 1 describes the socio-demographic characteristics of respondents (Table 1).

\begin{tabular}{|l|l|l|}
\hline Variable & Frequency(n=600) & Percentage (\%) \\
\hline Age & & \\
\hline $18-22$ & 508 & 84.7 \\
\hline $23-25$ & 92 & 15.3 \\
\hline Sex & & \\
\hline Male & 418 & 69.7 \\
\hline Female & 182 & 30.3 \\
\hline Department & & 59.8 \\
\hline Nursing & 359 & 40.2 \\
\hline Midwifery & 241 & 30 \\
\hline Academic year & & 53.5 \\
\hline Third year & 279 & \\
\hline Fourth year & 321 & 70.5 \\
\hline Residence & & \\
\hline Urban & 420 & \\
\hline Rural & & 50.5 \\
\hline & & \\
\hline
\end{tabular}

Table 1: Socio-demographic characteristics of respondents in Jigjiga and Haramaya University, Eastern Ethiopia January 10-30, 2013

\section{Knowledge related to universal precaution}

This study evaluated knowledge of students regarding universal precaution using different questions. The results showed that about $86.2 \%$ of the respondents had learned about infection prevention in the last one year. With respect to knowledge of respondents regarding blood borne pathogens only $37.7 \%$ knew that hepatitis $\mathrm{C}$ can be transmitted through needle stick /sharp injury, 69.8\% knew that hepatitis B can be transmitted through needle stick injury and $96.2 \%$ knew that HIV can be transmitted through needle stick injury. Four hundred fifty (75\%) respondents agreed that glove use for all patient care contacts is a useful strategy for reducing risk of transmission of microorganism. 
Citation: Yeshitila M, Mengistie B, Demessie A, Godana W (2015) Prevalence and Associated Factors of Needle Stick Injury among Nursing and Midwifery Students an Haramaya and Jigjiga University, Eastern Ethiopia. Primary Health Care 5: 186. doi:10.4172/2167-1079.1000186

Page 3 of 6

\section{Practice of universal precaution}

Regarding hand washing practice, 243(40.5\%) respondents washed their hands before touching patient or his/her surrounding always. Five hundred eight students (84.7\%) washed their hands after finishing work in hospital. Plain soap and water were used by 396(66\%) of the respondents to clean their hands either before or after procedure.

Concerning glove use, 437 (72.8\%) of the respondents indicated that they use glove for all people when ever needed while 541 (90.2 \%) of the respondents expressed wearing glove during disposing contaminated sharps and needles. Needle recapping with both hands was practiced by 264 (44\%) students. Overall, 250 (41.7\%) practiced Separating the needle from the syringe prior to disposal. Four hundred sixty seven $(77.8 \%)$ respondents throw used needles or sharps immediately in to the sharp bin (safety box). Only $31.8 \%$ students reported that safety box was the material that they used to dispose used needles and other sharp without disassembling.

\section{Prevalence of occupational exposures}

The one year prevalence of one or more needle sticks/sharp injury was $377(62.8 \%)$. The life time risk of needle stick injury was $389(64.8 \%)$. Two hundred and fourteen students (35.7\%) were exposed to blood/body fluid splashes either to the eye, mouth, or nose in the past 12 months and the life time risk of exposure to blood/body fluid splash was 230(38.3\%). Two hundred and sixty six respondents $(72.9 \%)$ were not wearing glove at the time of the injury. From the total respondents $150(48.1 \%)$ did not know the virus status of the source of their last injury, while $32(10.2 \%)$ of the source of the respondents last injury were positive to HIV and HBV (Table 2).

\begin{tabular}{|l|l|}
\hline Items & Percentage (\%) \\
\hline Ever had needle stick/ sharp injury & $64.8 \%(389)$ \\
\hline $\begin{array}{l}\text { Had needle stick/sharp injury in the last one } \\
\text { year? }\end{array}$ & $62.8 \%(377)$ \\
\hline Work place at injury time & \\
\hline Emergency department & $39 \%(147)$ \\
\hline Medical ward & $27.1 \%(102)$ \\
\hline Labour ward & $16.7 \%(63)$ \\
\hline Surgical ward & $10.1 \%(38)$ \\
\hline Intensive care unit & $5.8 \%(22)$ \\
\hline Operation theatre & $1.3 \%(5)$ \\
\hline $\begin{array}{l}\text { Reasons for the last needle stick injury in the last } \\
\text { one year? }\end{array}$ & \\
\hline Injection & $23.3 \%(88)$ \\
\hline Sudden movement of the patient & $18.3 \%(69)$ \\
\hline Suturing & $6.2 \%(46)$ \\
\hline Intravenous line & $9.5 \%(36)$ \\
\hline During recapping & \\
\hline During handling and collection of wastes & \\
\hline Surgical instruments & $23)$ \\
\hline
\end{tabular}

\begin{tabular}{|l|l|}
\hline $\begin{array}{l}\text { Ever had blood/body fluids splashing to your } \\
\text { mouth or eyes }\end{array}$ & $38.3 \%(230)$ \\
\hline $\begin{array}{l}\text { Splashing of blood or body fluids to your mouth or } \\
\text { eyes in the last one year? }\end{array}$ & $35.7 \%(214)$ \\
\hline $\begin{array}{l}\text { measures taken after exposure to needle stick } \\
\text { injury }\end{array}$ & \\
\hline Washing with soap and water & $19.1 \%(41)$ \\
\hline Wash with iodine or alcohol solution & $29.3 \%(63)$ \\
\hline Get tested for HIV & $22.3 \%(48)$ \\
\hline Seek post exposure prophylaxis (PEP) & $0.4 \%(1)$ \\
\hline Take tetanus anti-toxoid (TAT) & $7.9 \%(17)$ \\
\hline Applying pressure to stop bleeding & $3.7 \%(8)$ \\
\hline No measures taken & $12.6 \%(28)$ \\
\hline
\end{tabular}

Table 2: Prevalence of occupational exposures and measures taken by respondents among nursing and midwifery students in Haramaya and Jigjiga University, Eastern Ethiopia January10-20, 2013

\section{Management of occupational exposures}

Among the study participants $79.8 \%$ believed that needle stick injuries and blood and body fluid splash accidents should be reported to the responsible body. Two hundred and nineteen respondents (58.1\%) had reported the incident to the responsible body. However, only16 (7.4\%) seeked post exposure prophylaxis (PEP). The measures taken by students after needle stick or sharp injury includes washing with water and soap $41(19.1 \%)$, washing with alcohol or chlorine solution $63(29.3 \%)$, pressing immediately the injured site to stop bleeding 8 (3.7\%), squeezing to make it bleed more and evacuate 10(4.7\%), taking TAT prophylaxis 17 (7.9\%), counseling and testing for HIV $48(22.3 \%)$, taking post exposure prophylaxis $1(0.4 \%)$ and no measures taken $28(12.6 \%)$.

Most common reasons for not reporting the incident to the responsible body as stated by the students were the students did not think that it was important to report the incident 84 (53.5\%) and lack of awareness about the reporting system at all 29(18.5\%).

\section{Reasons for needle stick injury}

Students were asked about various circumstances that could contribute for needle stick injury. These included lack of personal protective equipment 145 (24.2\%), overcrowded work place 104(17.3\%), lack of experience and knowledge about procedure conducted $68(11.3 \%)$, lack of supervision by instructors $88(14.7 \%)$, and technical error committed by the student $88(14.7 \%)$. Shortage of glove was reported by $77.8 \%$ of respondents during practical sessions. Among students who suffered from one or more needle stick/sharp injury in the past one year, most of the incident occurred in emergency $142(39 \%)$ and medical ward $98(27.1 \%)$. The most prominent reasons for injuries were during administration of injection $88(23.3 \%)$ and sudden movement of the patient during procedures 84 (22.3\%).

Fear to give care to any patient due to occupational exposure was reported by $46.8 \%$ of respondents. Overall, $33.7 \%$ of respondents expressed their desire to leave nursing school due to fear of catching disease during clinical practice. Majority of the respondents (67\%) 
Citation: Yeshitila M, Mengistie B, Demessie A, Godana W (2015) Prevalence and Associated Factors of Needle Stick Injury among Nursing and Midwifery Students an Haramaya and Jigjiga University, Eastern Ethiopia. Primary Health Care 5: 186. doi:10.4172/2167-1079.1000186

Page 4 of 6

expressed their worry more during clinical practice than in class room .Two hundred seventy seven students (46.2\%) have fear to give nursing care for known HIV positive patients.

\section{Predictors of needle stick injury}

On bivariate analysis, independent predictors that were found to be significantly associated with needle stick/sharp injury include age, sex, academic year, family residence, receiving infection prevention training, importance of glove use for every patient care, disassembling used needle prior to disposal, injury place, .

The results of the multivariate analysis indicated that exposure to needle stick/ sharp injury was significantly associated with males
(AOR 1.56, 95\% CI1.07-2.275). Male students were 1.56 times more likely to be exposed to needle stick/sharp injury than female students. Urban Family Residence was significantly associated with exposure to needle stick/sharp injury at (AOR 2, 95\% CI 1.18 - 2.422).

Learning about infection prevention/ universal precaution was also associated with exposure to needle stick/sharp injury (AOR 0.44, 95\% CI 0.17 - 1.17). Those students who had learned about infection prevention were 0.44 times less likely to be exposed to needle stick/ sharp injury than those who did not learn. Students who separate (disassemble) used needles before disposal were 2 times more likely to be exposed to needle stick/sharp injury than those who did not disassemble at all (AOR 1.55, 95\% CI 1.09-2.204) (Table 3).

\begin{tabular}{|c|c|c|c|c|c|}
\hline \multirow[b]{2}{*}{ Variables } & \multicolumn{2}{|c|}{ Needle stick/sharp injury } & \multirow[b]{2}{*}{$\operatorname{COR}(95 \% \mathrm{Cl})$} & \multirow[b]{2}{*}{ AOR $(95 \% \mathrm{Cl})$} & \multirow[b]{2}{*}{ P Value } \\
\hline & Exposed $\mathrm{N}(\%)$ & Not Exposed N (\%) & & & \\
\hline \multicolumn{6}{|l|}{ Sex } \\
\hline Male & $273(65.3 \%)$ & $145(34.7 \%)$ & $0.59(0.42-0.85)$ & $1.56(1.07-2.275)$ & \multirow{2}{*}{$0.021^{*}$} \\
\hline Female & $96(52.7 \%)$ & $86(47.3 \%)$ & 1 & 1 & \\
\hline \multicolumn{6}{|c|}{ Residence } \\
\hline Urban & $254(60.5 \%)$ & $166(39.5 \%)$ & $1.87(1.31-2.67)$ & $2(1.18-2.422)$ & \multirow{2}{*}{$0.004^{*}$} \\
\hline Rural & $115(63.9 \%)$ & $65(36.1 \%)$ & 1 & 1 & \\
\hline \multicolumn{6}{|c|}{ Ever learned infection prevention } \\
\hline Yes & $326(63.1 \%)$ & $191(36.9 \%)$ & $0.6(0.23-1.54)$ & $0.44(0.17-1.17)$ & \multirow{2}{*}{$<0.005^{*}$} \\
\hline No & $43(51.8 \%)$ & $40(48.2 \%)$ & 1 & 1 & \\
\hline \multicolumn{6}{|c|}{$\begin{array}{l}\text { Glove use for all patient care is } \\
\text { useful }\end{array}$} \\
\hline 1.yes & $267(59.3 \%)$ & $183(40.7 \%)$ & $1.58(1.091-2.306)$ & $1.24(0.34-4.56)$ & \multirow{2}{*}{0.742} \\
\hline 2.No & $102(32 \%)$ & $48(68 \%)$ & 1 & 1 & \\
\hline \multicolumn{6}{|c|}{$\begin{array}{l}\text { Separate used needles before } \\
\text { disposal }\end{array}$} \\
\hline Yes & $165(66 \%)$ & $85(34 \%)$ & $0.68(0.49-0.95)$ & $1.55(1.09-2.204)$ & \multirow{2}{*}{$0.013^{*}$} \\
\hline No & $204(58.3 \%)$ & $146(41.7 \%)$ & 1 & 1 & \\
\hline \multicolumn{6}{|c|}{ Recap used needle } \\
\hline Yes & $151(52.7 \%)$ & $113(47.3 \%)$ & $0.72(0.519-1.007)$ & $0.72(0.513-1.02)$ & \multirow{2}{*}{0.067} \\
\hline No & $218(64.9)$ & $118(35.1 \%)$ & 1 & 1 & \\
\hline \multicolumn{6}{|c|}{ Academic year } \\
\hline 3rd year & $172(61.6 \%)$ & $107(38.4 \%)$ & $1.58(1.130-2.203)$ & $1.13(0.35-3.642)$ & \multirow{2}{*}{0.833} \\
\hline 4th year & $197(61.4 \%)$ & $124(38.6 \%)$ & 1 & 1 & \\
\hline
\end{tabular}

Table 3: predictors of exposure to needle stick injury in past one year among nursing and Midwifery students in Haramaya and Jigjiga University, Eastern Ethiopia January, 2013

\section{Discussion}

In this study high level of occupational exposure to needle stick/ sharp injury was detected. Life time exposure of needle stick/sharp injury was $64.8 \%$ and one year self-reported needle stick injury was 62.8\%. Sex (male), family residence (urban), learning about infection prevention and disassembling used needles prior to disposal were found to be associated with needle stick/sharp injury. 
Page 5 of 6

According to this study one year self-reported prevalence of needle stick injury was $62.8 \%$ this finding is comparative to the report from Iran where $70 \%$ of the subjects had experienced at least one NSIs during the past 12 months [5].This result is lower than a crosssectional descriptive study conducted in Delhi where $79.5 \%$ of students were exposed to needle stick injury in the past 12 months [6].This high prevalence of needle stick injury could be attributed to the risky habit of the students like separating or disassembling used needles prior to disposal, a factor identified to be associated with occurrence of needle stick injuries. Other possible reasons for high prevalence of needle stick injuries include lack of adequate PPEs, lack of knowledge and skill about the procedure performed and nonadherence to standard precautions.

The one year prevalence of exposure to blood and body fluid was $35.7 \%$, whereas life time risk of exposure to blood/body fluid splash was $38.3 \%$. This result is lower as compared to the South Africa report where $87.1 \%$ reported exposure to body fluids or blood sometime in the past while $50.9 \%$ reported exposure within the last six months respectively [7]. However, this result is higher from the Korean report where splash accident accounts for $13.9 \%$ [8]. This difference in prevalence could be due to the difference in socio economic status of the countries that could have direct impact to supply of personal protective equipment such as glove, goggle, mask, etc.

In this study females were less likely to be exposed to needle stick injury as compared to males AOR 1.56(1.07-2.275). This is similar to the report from Eastern Ethiopia conducted on health workers where males were 1.75 times more exposed than females to needle stick injury with (AOR 1.75, CI 1.04-2.92) [9]. However this was not consistent study conducted in Kenya where accidental exposures were more frequently reported by females [10].

In this study, learning about infection prevention/ universal precaution was associated with exposure to needle sick/sharp injury with (AOR 0.44 CI 0.17-1.17). Taking training in the last one year was found to be protective from exposure to needle stick injuries. This is consistent with a study from Uganda [11]. Descriptive study conducted in Nigeria showed that nursing and midwifery students had poor knowledge of WHO recommended universal precaution for preventing HIV transmission [12]. Learning about infection prevention enhances awareness and compliance of universal precautions among students.

Students who practiced disassembling of used needles were 2 times more likely exposed to needle stick injuries than those who did not practiced disassembling (AOR 1.55, 95\% CI 1.09-2.204). In this study risky behavior of students such as needle recapping by both hands was observed in $44 \%$ of the students. However, it was not significantly associated with needle stick/sharp injuries. This finding is consistent with a cross-sectional study that was conducted in Iran [5].

Reasons mentioned by the students for exposure to needle stick injury include lack of personal protective equipment, overcrowded work place, lack of experience and knowledge about procedure conducted, lack of supervision by instructors and technical error committed by the student. This is in agreement to a cross-sectional quantitative survey conducted in South Africa [7]. All the above reasons listed by the participants are avoidable and manageable, if done properly they could have positive impact in minimizing the incidence of needle stick injury.

According to the results of this study among students who suffered from one or more needle stick/sharp injury in the past one year most of the incident occurred in emergency and medical ward. This is consistent with research done in Taiwan where largest number of needle stick injuries occurred in outpatient departments $50 \%$ and emergency department $37.5 \%$ [13].This could be because of the fact that especially at emergency departments the nursing cares provided are lifesaving and crisis management. This could cause pressure and stress and demand fast response from students.

Wearing gloves is known to be an important line of defense but $72.9 \%$ were not wearing glove at the time of injury. This is consistent to the study from India [6]. This could be due to shortage of PPE which was described as a reason by the respondents.

Timely reporting of occupational exposures to a responsible body is required to ensure appropriate counseling and to facilitate prophylaxis or early treatment. $79.8 \%$ participants of this study believed that needle stick injuries and blood and body fluid splash accidents should be reported to the responsible body, However $41.9 \%$ of the occupational exposures were not reported to the responsible body. Similarly a cross sectional study that was conducted in Serdang Hospital Malaysia by showed that $99.1 \%$ of the respondents agreed that needle stick and sharps injury needs to be reported, However, out of those health care workers $23.5 \%$ who had needle stick injury only $30.9 \%$ had reported the incident [4]. This is an indication for the existing gaps between knowledge and practice among the health care workers regarding injury reporting and the same is true with the students.

\section{Conclusion}

High rate of exposure to blood and body fluid was demonstrated among nursing and midwifery students. Family Residence (urban), sex (male), learning about universal precaution, and disassembling used needles prior to disposal, were predictors for needle stick injury.

Majority of the students had risky practices such as needle recapping, disassembling of used needles. Discriminatory behaviors such as fear to give nursing care for HIV positive patients were also observed among respondents.

This result also indicated that students lack adequate knowledge regarding specific post exposure measures that should be taken. Most needle stick injuries were not reported to the responsible bodies. The most common reasons for not reporting the incident to the responsible body as stated by the students were, the students did not think that it was important to report the incident and lack of awareness about the reporting system at all. Intensive education programs directed at students to increase their awareness and compliance with Universal Precautions should be implemented. There should be a standard protocol for provision of post exposure counseling and treatment available at every hospital. Establishment of a surveillance system for registering, reporting and management of Occupational exposure in hospitals is recommended.

\section{Author contributions}

My had made substantial contributions to conception, design, analysis and interpretation of data. She did major works in the research work. $\mathrm{BM}$ and $\mathrm{AD}$ contributed to the conception, design, data analysis, drafting and approval of the manuscript. WG participated in interpretation of the findings, contributed to the drafting and writing of the paper, critical writing and revision of the manuscript and updated the manuscript to this version. All authors read and approved the manuscript. 
Citation: Yeshitila M, Mengistie B, Demessie A, Godana W (2015) Prevalence and Associated Factors of Needle Stick Injury among Nursing and Midwifery Students an Haramaya and Jigjiga University, Eastern Ethiopia. Primary Health Care 5: 186. doi:10.4172/2167-1079.1000186

Page 6 of 6

\section{Acknowledgment}

We would like to express my gratitude to Haramaya University for funding this research. Our acknowledgment also goes to study participants for their willingness in providing valuable information. Last but not least we would like to acknowledge families, friends, School of Nursing and Midwifery for their encouragement and support.

\section{References}

1. Amosu A.M , A.M. Degun, N.O.S. Atuloma (2003) The Level of Knowledge Regarding Occupational Hazards among Nurses in Abeokuta, Ogun State, Nigeria. African Journal of Medical Science 11:1.

2. Fazlollah G (2009) Needle Sticks / Sharps Injuries and Determinants in Nursing Care Workers. European Journal of Social Sciences.

3. Taimur S, Umair K, Sidra I (2010) Knowledge, attitudes and practices of medical students regarding needle stick injuries in Pakistan. Journal of Pakistan medical association 20: 6 .

4. Lekhraj R (2010) Needle Stick and Sharps Injuries and Factors Associated Among Health Care Workers in a Malaysian Hospital. European Journal of Social Sciences 13.

5. Hadadi A, Afhami S, Karbakhsh M (2008) Occupational exposure to body fluids among healthcare workers in iran. Singapore Medical Journal 49: 492 .
6. Rasania SK, Anita Verma, Saudan Singh (2008) Study of Prevalence and Response to Needle Stick Injuries among Health Care Workers in a Tertiary Care Hospital in Delhi, India. Indian J Community Med 35: 7477.

7. Zungu LI (2008) Knowledge and experiences of needle prick injuries (NPI) among nursing students at a university in Gauteng, South Africa South Africa Med Journal 50.

8. Smith DR, McGeer A , Simor AE, Low DE (2006) Epidemiology of needle sticks and Sharps Injuries among Professional Korean Nurses. International Journal of Occupational Safety Ergon 11: 431-440.

9. Ayalu AR., Shiferaw F (2010) Standard Precautions: Occupational Exposure and Behavior of Health Care Workers in Ethiopia. 5: 14420

10. Everline M, Zipporah N (2010) Prevalence and factors associated with percutaneous injuries and splash exposures among health-care workers in a provincial hospital, Kenya. The Pan African Medical Journal 14:10.

11. Hulme P (2008) Incidence of Needle stick injuries among Ugandan student nurses in a rural hospital.

12. Atulomah NO, Oladepo (2003) Knowledge, Perception and Practice with Regards to Occupational Risks of HIV/AIDS among Nursing and Midwifery Students in Ibadan, Nigeria.African Journal of Medical Science 31: 223-7.

13. Ya-Hui Y, Ming-Tsang W (2004) Needle stick/sharps injuries among vocational school nursing students in southern Taiwan. American Journal of Infection Control 32: 431-435. 